\title{
Fourier Transform Infrared Spectroscopy Monitoring of Dihydroartemisinin-Induced Growth Inhibition in Ovarian Cancer Cells and Normal Ovarian Surface Epithelial Cells
}

This article was published in the following Dove Press journal:

Cancer Management and Research

Lei $\mathrm{Li},{ }^{\prime}$ Jinguang $\mathrm{Wu},{ }^{2}$ Shifu Weng, ${ }^{2}$ Limin Yang, ${ }^{3}$ Huizi Wang, ${ }^{4}$ Yizhuang $\mathrm{Xu},{ }^{2}$ Keng Shen'

'Department of Obstetrics and Gynecology, Peking Union Medical College Hospital,

Chinese Academy of Medical Sciences and Peking Union Medical College, Beijing 100730, People's Republic of China; ${ }^{2}$ Beijing National Laboratory for Molecular Sciences, State Key Laboratory for Rare Earth Materials Chemistry and Applications, College of Chemistry and Molecular Engineering, Peking University, Beijing 10087I, People's Republic of China; ${ }^{3}$ State Key Laboratory of Nuclear Physics and Technology, Institute of Heavy lon Physics, School of Physics, Peking University, Beijing 10087I, People's Republic of China; ${ }^{4}$ Medical Science Research Center, Peking Union Medical College Hospital, Chinese Academy of Medical Sciences and Peking Union Medical College, Beijing 100730, People's Republic of China

Correspondence: Keng Shen

Department of Obstetrics and

Gynecology, Peking Union Medical

College Hospital, Chinese Academy of

Medical Sciences and Peking Union

Medical College, No. I Shuai Fu Yuan,

Eastern District, Beijing 100730, People's

Republic of China

Tel +86 106915 6204

Fax +86 10 6915 5653

Email kengshen_pumch@sina.com

Yizhuang $\mathrm{Xu}$

Beijing National Laboratory for Molecular Sciences, State Key Laboratory for Rare

Earth Materials Chemistry and

Applications, College of Chemistry and

Molecular Engineering, Peking University,

No. 202 Chengfu Road, Haidian District,

Beijing I0087I, People's Republic of China

Tel +861062752689

Email xuyzh_peking@sina.com
Purpose: Ovarian cancer is the most lethal of gynecological malignancies. Dihydroartemisinin (DHA), a derivative of artemisinin (ARS), has profound effects against human tumors. The aim of this study was to provide a convenient, cost-efficient technique, Fourier transform infrared (FTIR) spectroscopy, to monitor and evaluate responses to DHA-induced growth inhibition of ovarian cancer cells.

Methods: Cell growth and viability and the 50\% inhibitory concentration (IC50) of DHA were assessed by the MTT assay. FTIR spectroscopy was used to monitor cells following DHA treatment, and data were analyzed by OMNIC 8.0 software.

Results: DHA can decrease the viability of ovarian cancer cells and normal cells, but cancer cells were more sensitive to this drug than normal cells. Spectral differences were observed between cells with or without DHA treatment. In particular, an increase in the amount of lipids and nucleic acids was observed. The band intensity ratio of 1454/1400, and the intensity of the band $1741 \mathrm{~cm}^{-1}$ increased, indicating stronger absorption after DHA treatment. Moreover, the differences were larger for the cell lines that were more sensitive to DHA.

Conclusion: The spectral features provided information about important molecular characteristics of the cells in response to chemicals. These findings demonstrated the possible use of FTIR spectroscopy to evaluate DHA-induced growth inhibition effects in ovarian cancer cells and provided a promising new tool for monitoring cell growth and the effects of antitumor drugs in the clinic in the future.

Keywords: ovarian cancer, artemisinin, ARS, dihydroartemisinin, DHA, fourier transform infrared spectroscopy, FTIR spectroscopy, growth inhibition

\section{Introduction}

Ovarian cancer is the most lethal gynecologic malignancy, accounting for 295,414 new diagnoses and 184,799 deaths annually worldwide. ${ }^{1}$ Due to the lack of obvious symptoms in the early stage and its highly metastatic and recurrent nature, approximately $70 \%$ of ovarian cancer patients are diagnosed at stage III or IV, resulting in five-year survival rates less than $30 \%{ }^{2}$ Numerous studies have been conducted to evaluate several conventional chemotherapeutic drugs for ovarian cancer treatment, such as paclitaxel and platinumbased drug therapy. ${ }^{3}$ However, the efficacy has not improved significantly because of the low response rates, cytotoxic side effects and chemoresistance. ${ }^{4}$ Therefore, it is essential to develop safer and more effective methods for ovarian cancer therapy. 
Artemisinin (ARS), a natural sesquiterpene endoperoxide extracted from the goldenrod Artemisia annиa $\mathrm{L}$ in China, is widely used in malaria treatment. ${ }^{5,6}$ It has been demonstrated that ARS and its derivatives, such as dihydroartemisinin (DHA), show antitumor activities. ${ }^{7,8}$ These compounds participate in a series of cellular biochemical processes, including cell proliferation and apoptosis, oxidative stress and selective cytotoxicity of cancer cells. ${ }^{9,10}$ Previous studies have reported extensive examinations of ARS and its analogs in ovarian, prostate, pancreatic, breast and liver cancers or cells and showed little cytotoxicity and strong synergistic anticancer effects when combined with conventional chemotherapeutic agents. ${ }^{8,11-14}$

In this study, we investigated the antitumor effects of DHA, one of the analogs of ARS, on the cell proliferation and inhibition of ovarian cancer cells. We also examined the alterations in cellular molecules such as proteins, lipids and nucleic acids using Fourier transform infrared (FTIR) spectroscopy after DHA exposure. FTIR spectroscopy is a vibrational spectroscopic technique that detects the chemical components of a cell sample. ${ }^{15,16}$ This convenient, simple and noninvasive method can not only distinguish normal tissues from cancer tissues but also distinguish cell signatures via responses to antitumor drugs. ${ }^{17-19}$ We explored the effects of DHA on ovarian cancer cells using FTIR spectroscopy for the first time, which could provide new insights into our understanding of DHA's antitumor effects.

\section{Methods}

\section{Cell Culture}

The normal human ovarian surface epithelial cell line (HOSEpiC) used in this study was purchased from ScienCell Research Laboratories (San Diego, CA) and cultured in RPMI-1640 medium (HyClone, Logan, Utah, USA) supplemented with $15 \%$ heat-inactivated fetal bovine serum (FBS; Gibco, Carlsbad, CA, USA) at $37{ }^{\circ} \mathrm{C}$ in $5 \%$ carbon dioxide. The ovarian cancer cell lines used in this study were ES2, A2780 and IGROV1. ES2 and A2780 were obtained from the Cell Support Center, Institute of Basic Medical Science, Chinese Academy of Medical Sciences, and IGROV1 was obtained from the NIH cell bank. A2780 and IGROV1 cells were cultured in RPMI-1640 medium with $10 \%$ FBS, and ES2 cells were incubated in McCoy's 5A medium (HyClone) with 10\% FBS. Each of the cell lines were harvested at similar times after two passages. The DHA compound (Sigma-Aldrich, Bornem, Belgium) was dissolved in sterile DMSO.

\section{Cell Viability Assay}

The conventional MTT assay was used to assess cell growth and viability. Generally, cells were cultured $\left(5 \times 10^{3}\right.$ cells/ well) in 96-well plates and treated with DHA at different concentrations $(0 \mu \mathrm{M}, 2.5 \mu \mathrm{M}, 5 \mu \mathrm{M}, 10 \mu \mathrm{M}, 20 \mu \mathrm{M}, 50 \mu \mathrm{M}$, $100 \mu \mathrm{M}, 200 \mu \mathrm{M})$ for $48 \mathrm{hr}$. Each concentration of DHA was added to each cell line in at least six duplicate wells. The MTT assay was performed according to the instructions. IC20, IC50 and IC80 for each cell line were calculated using SPSS 17.0 software (Chicago, Illinois, USA). The experiment was repeated at least three times.

\section{Cell Preparation for Spectroscopy}

After cells were cultured in $25 \mathrm{~cm}^{2}$ flasks with or without DHA at their IC50 concentrations for $48 \mathrm{hr}$, they were detached by trypsinization and centrifuged at $1000 \mathrm{rpm}$ for $5 \mathrm{~min}$. The supernatant was discarded and the cells were stored at $-80{ }^{\circ} \mathrm{C}$ until removal for testing.

\section{FTIR Spectroscopy and Data Analysis}

FTIR measurements were carried out using a NICOLET iN10 MX FTIR spectrometer (Thermo Scientific, Waltham, MA, USA) equipped with a $\mathrm{KBr} / \mathrm{Ge}$ beam splitter and a mercury cadmium telluride (MCT) detector. All spectra were recorded in the range of $4000-600 \mathrm{~cm}^{-1}$ with a resolution of $4 \mathrm{~cm}^{-1}$ and 16 scans. For each sample, we detected at least three times, and a representative spectrum was presented for the following analyses. Each spectrum was initially baseline corrected and normalized for the intensity spanning from 0 to 1 to obtain a better comparison between spectra. The experiment of capturing the spectra of cells with or without DHA treatment was also repeated at least three times.

To further compare the spectral differences between cells with and without DHA treatment, the spectrum of cells without DHA treatment was subtracted by the spectrum of cells of the same cell line treated with DHA for $48 \mathrm{hr}$. Thus, we obtained the subtraction spectra. Note that the subtraction spectra were obtained using preprocessed spectra, which were baseline corrected and normalized from 0 to 1 .

\section{Statistical Analysis}

The IC20, IC50 and IC80 of DHA are expressed as the mean \pm SEM from three separate experiments. For statistical comparisons among multiple cell lines of different concentrations, one-way ANOVA was performed by SPSS 17.0 software (Chicago, Illinois, USA). For statistical comparisons of spectral intensities between DHA treatment and vehicle controls, 
Student's $t$-test was performed by SPSS. A $P$ value $<0.05$ was considered statistically significant.

\section{Results}

\section{DHA Decreased the Viability of Ovarian} Cancer Cells and Normal Cells

After exposure to DHA for $48 \mathrm{hr}$, the cell viability of the four cell lines was greatly decreased (Figure 1). The growth of ES2 and A2780 cells showed the greatest decrease with lower IC20, IC50 and IC80 values than the other two cell lines (Figure 1A and B, Table 1). DHA had the greatest effects on cell growth, with the percentage decrease in viability of ES2 cells ranging from $12 \%(2.5 \mu \mathrm{M})$ to $100 \%(200 \mu \mathrm{M})$ and that of A2780 cells ranging from $20 \%(2.5 \mu \mathrm{M})$ to $83 \%(200 \mu \mathrm{M})$. IGROV1 cells appeared to be less sensitive to this drug in the three cancer cell lines, as these cells showed significantly lower IC50 values than ES2 and A2780 cells (Figure 1C, Table 1). HOSEpiC cells were the least sensitive to DHA of the four cell lines. The growth of HOSEpiC was inhibited slightly by $0 \%(2.5 \mu \mathrm{M})$ to $51 \%(200 \mu \mathrm{M})$, and the IC20, IC50 and IC80 values were higher than those of the three ovarian cancer cell lines (Figure 1D, Table 1). These results suggested that DHA produced different inhibitory effects on ovarian cancer cells and normal cells, as DHA greatly decreased the growth of ovarian cancer cells while having weaker effects on HOSEpiC cells.

\section{FTIR Spectra of Ovarian Cancer Cells and Normal Cells with or Without DHA Treatment}

To investigate the molecular changes after exposure to DHA, FTIR spectral analysis was performed on ovarian cancer cells and normal cells treated with DHA at the concentrations corresponding to their IC50 for $48 \mathrm{hr}$. Typical spectra with or without treatment for each of the cell lines are presented in Figure 2. Notable spectral differences were found after DHA exposure, particularly in the $3000-2800 \mathrm{~cm}^{-1}, 1800-1700 \mathrm{~cm}^{-1}, 1500-1300 \mathrm{~cm}^{-1}$ and $1300-900 \mathrm{~cm}^{-1}$ regions for all of the cell lines. The intensities of specific bands, which could be used as spectral markers for cells, were also calculated and compared in Figure 3.

The band signals at $3000-2800 \mathrm{~cm}^{-1}$ are dominated by asymmetric and symmetric stretching vibrations of $\mathrm{CH}_{3}$ and $\mathrm{CH}_{2}$ groups, attributed to alkyl chains primarily present in lipids. ${ }^{18}$ The intensity of FTIR spectra in this region
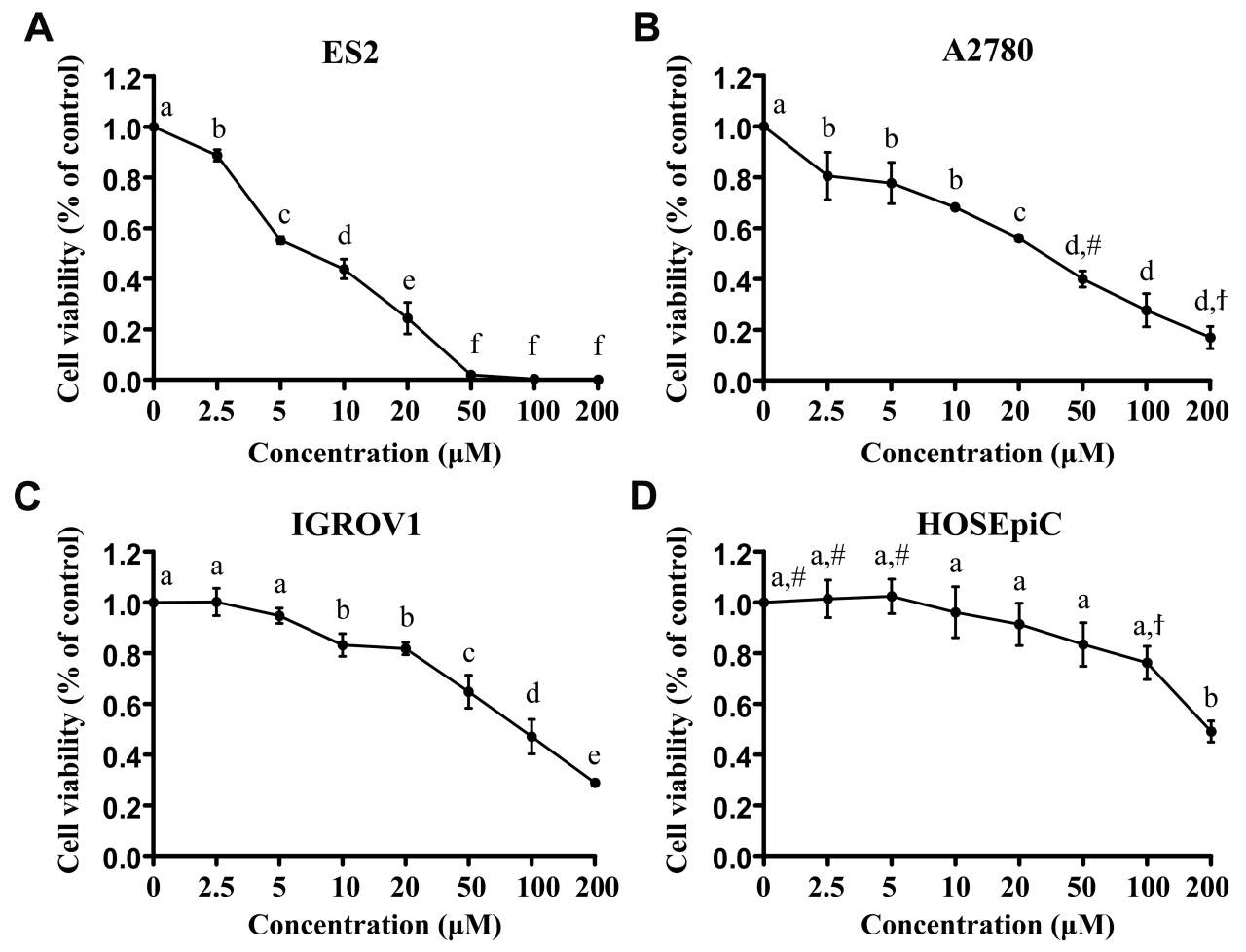

D

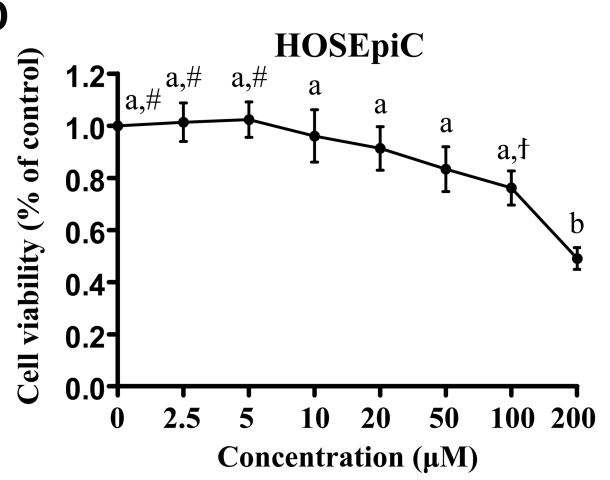

Figure I DHA decreased the viability of ovarian cancer cells and normal cells. DHA inhibited the growth of human ovarian carcinoma cells ES2 (A), A2780 (B) and IGROVI (C), and ovarian surface epithelial cells HOSEpiC (D) after $48 \mathrm{hr}$ of exposure, as assessed by the MTT assay. Each value is presented as the percentage of cell viability while control cells were defined as $100 \%$ viable. Error bars represent the SEM, $n=3 .{ }^{a-f} P<0.05$ between each other; ${ }^{\#,}{ }^{\dagger} P<0.05$. 
Table I Growth Inhibitory Effect of DHA on Ovarian Cancer Cells and Normal Cells

\begin{tabular}{|l|l|l|l|l|}
\hline \multirow{2}{*}{ Inhibitory Concentration* } & \multicolumn{4}{l}{ DHA Concentration $(\mu \mathrm{M}) * *$} \\
\cline { 2 - 5 } & ES2 & A2780 & IGROVI & HOSEpiC \\
\hline IC20 & $3.68 \pm 0.58^{\mathrm{a}}$ & $14.25 \pm 3.72^{\#}$ & $34.87 \pm 14.29^{\mathrm{b}}$ & $61.34 \pm 17.49^{\mathrm{b}, \mathrm{f}}$ \\
IC50 & $8.77 \pm 1.23^{\mathrm{a}}$ & $49.45 \pm 3.05^{\mathrm{a}}$ & $98.84 \pm 20.58^{\mathrm{b}}$ & $266.81 \pm 17.10^{\mathrm{c}}$ \\
IC80 & $20.91 \pm 2.60^{\mathrm{a}}$ & $184.33 \pm 21.97^{\mathrm{a}}$ & $319.23 \pm 76.60^{\mathrm{a}}$ & $1440.26 \pm 258.37^{\mathrm{b}}$ \\
\hline
\end{tabular}

Notes: *IC20, IC50 and IC80 are defined as the concentrations of DHA that suppress cell growth by $20 \%, 50 \%$ and $80 \%$, respectively, relative to the control cells. $* *$ Data \pm SEM. ${ }^{a-c} p<0.05$ between each other for each IC. ${ }^{\#,}{ }^{\dagger} p<0.05$.

increased after DHA exposure in each of the four cell lines (Figure 2). Higher relative intensities at $2925 \mathrm{~cm}^{-1}$ ( $v_{\text {asym }}$ $\left.\mathrm{CH}_{2}\right)$ and $2854 \mathrm{~cm}^{-1}\left(v_{\mathrm{sym}} \mathrm{CH}_{2}\right)$ were found in DHAtreated cells than in the vehicle control (Figure $3 \mathrm{~A}$ and $\mathrm{B}$ ), indicating an increased lipid content as a result of DHA treatment.

In the band signals between $1800-1700 \mathrm{~cm}^{-1}$, notable differences were found at the peak of $1741 \mathrm{~cm}^{-1}$, which is characteristic of ester $\mathrm{C}=\mathrm{O}$ stretching of phospholipids in the cell membrane. ${ }^{20}$ The absorption signals at $1741 \mathrm{~cm}^{-1}$ were strengthened after DHA treatment in each of the four cells (Figure 2). The band intensities of $1741 \mathrm{~cm}^{-1}$ were also increased; the differences were significant for ES2, A2780 and IGROV1 cells (Figure 3C), suggesting increased membrane lipid and esterified component levels in DHAtreated cancer cells. These increases in lipid content (data in the regions of both $3000-2800 \mathrm{~cm}^{-1}$ and $1800-1700 \mathrm{~cm}^{-1}$ ) were in agreement with the previous study showing that the band intensities at $3000-2800 \mathrm{~cm}^{-1}$ and the peak at $1741 \mathrm{~cm}^{-1}$ both tended to increase gradually with increasing 5-fluorouracil dose in MCF-7 cells (human breast adenocarcinoma cell line). ${ }^{21}$ This previous study demonstrated that the MCF-7 cell proliferation was more inhibited with the increase of 5-fluorouracil dose, and the higher intensities at $1741 \mathrm{~cm}^{-1}$ and in the region of $3000-2800 \mathrm{~cm}^{-1}$ were seen when the MCF-7 cells were more inhibited, consistent with our data showing that while DHA inhibited the growth of ovarian cancer cells and normal cells, higher intensities in these spectral regions were found in DHA-treated cells than in control cells.

The band signals at around $1454 \mathrm{~cm}^{-1}$ and $1400 \mathrm{~cm}^{-1}$, commonly characteristic of the $\mathrm{C}-\mathrm{H}$ bending vibrations of multiple amino acid side chains and lipids, are critical spectral features for differentiating normal, benign and malignant tissues. ${ }^{22,23}$ It is obvious that the intensity ratios of the two bands (1454/1400) were elevated after DHA exposure (Figure 3D), either because of the increased intensities of $1454 \mathrm{~cm}^{-1}$ (for ES2, IGROV1 and HOSEpiC cells) or because of the dramatically decreased intensity of $1400 \mathrm{~cm}^{-1}$ (for A2780 cells) (Figure 2). The differences were significant for ES2 and A2780 cells. As ES2 and A2780 cells showed more sensitivity to this drug in the above results, the intensity ratios of 1454/1400 were higher in these two cell lines than in IGROV1 and HOSEpiC cells after DHA treatment.

The spectral features at $1242 \mathrm{~cm}^{-1}$ and $1086 \mathrm{~cm}^{-1}$ included absorption bands characteristic of asymmetric and symmetric phosphodiester vibrations of nucleic acids. ${ }^{24}$ DHA treatment led to significantly higher intensities at $1242 \mathrm{~cm}^{-1}$ for ES2 and A2780 cells and significantly higher intensities at $1086 \mathrm{~cm}^{-1}$ for the four cell lines than for their vehicle controls (Figure 2, 3E and F). These results suggested an increase in nucleic acids under DHA treatment.

From the above results, it is also obvious that the spectral differences between control and DHA-treated cells were larger in ES2 and A2780 cells than in IGROV1 and HOSEpiC cells. This finding might be because DHA greatly inhibited the growth of ES2 and A2780 cells, and IGROV1 and HOSEpiC cells seemed less sensitive to this drug.

\section{Subtraction Spectra of the Cell Lines with or Without DHA Treatment}

To further compare the differences between cells with and without DHA treatment, subtraction spectra were obtained for each of the cell lines with DHA vs. the corresponding control. The subtle differences between the two samples can be clearly observed from the subtraction spectrum. Positive and negative bands directly indicate that the content of the related components in the former cell line is higher or lower, respectively, than that in the control cells. ${ }^{25}$ As shown in Figure 4 (the subtraction spectrum of the cell line treated with DHA minus its control for each of the four cell lines), positive bands at around $2925 \mathrm{~cm}^{-1}, 2854 \mathrm{~cm}^{-1}$ and $1740 \mathrm{~cm}^{-1}$ were observed, consistent with our above results. For the absorption bands at around $1242 \mathrm{~cm}^{-1}$ and $1086 \mathrm{~cm}^{-1}$, 

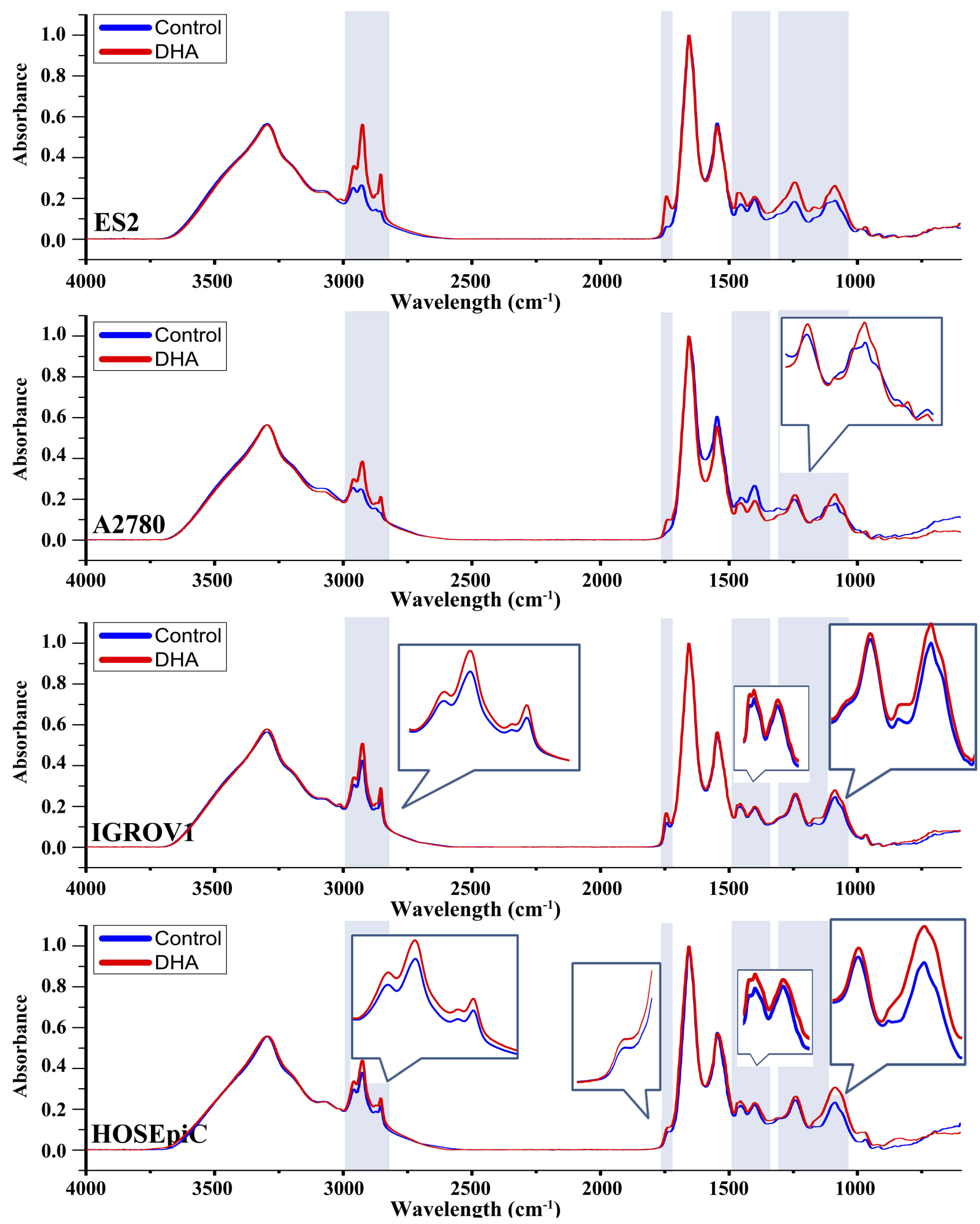

Figure 2 FTIR spectra of ovarian cancer cells (ES2, A2780 and IGROVI) and normal cells (HOSEpiC) treated with DHA. Cells were treated with or without DHA at the concentration corresponding to their IC50 for $48 \mathrm{hr}$. Typical spectra are presented in the region of 4000-600 $\mathrm{cm}^{-1}$ (control group: blue line; DHA group: red line). There were significant differences in the FTIR spectra of cells after exposure to DHA, especially in the regions of $3000-2800 \mathrm{~cm}^{-1}, 1800-1700 \mathrm{~cm}^{-1}, 1500-1300 \mathrm{~cm}^{-1}$ and $1300-900 \mathrm{~cm}^{-1}$, which are indicated in the blue background. Local spectral features that were not clearly observed are magnified in boxes. 


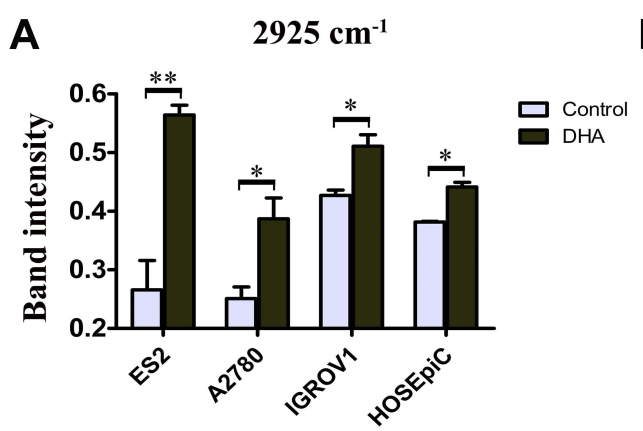
B
$2854 \mathrm{~cm}^{-1}$

C

$1741 \mathrm{~cm}^{-1}$
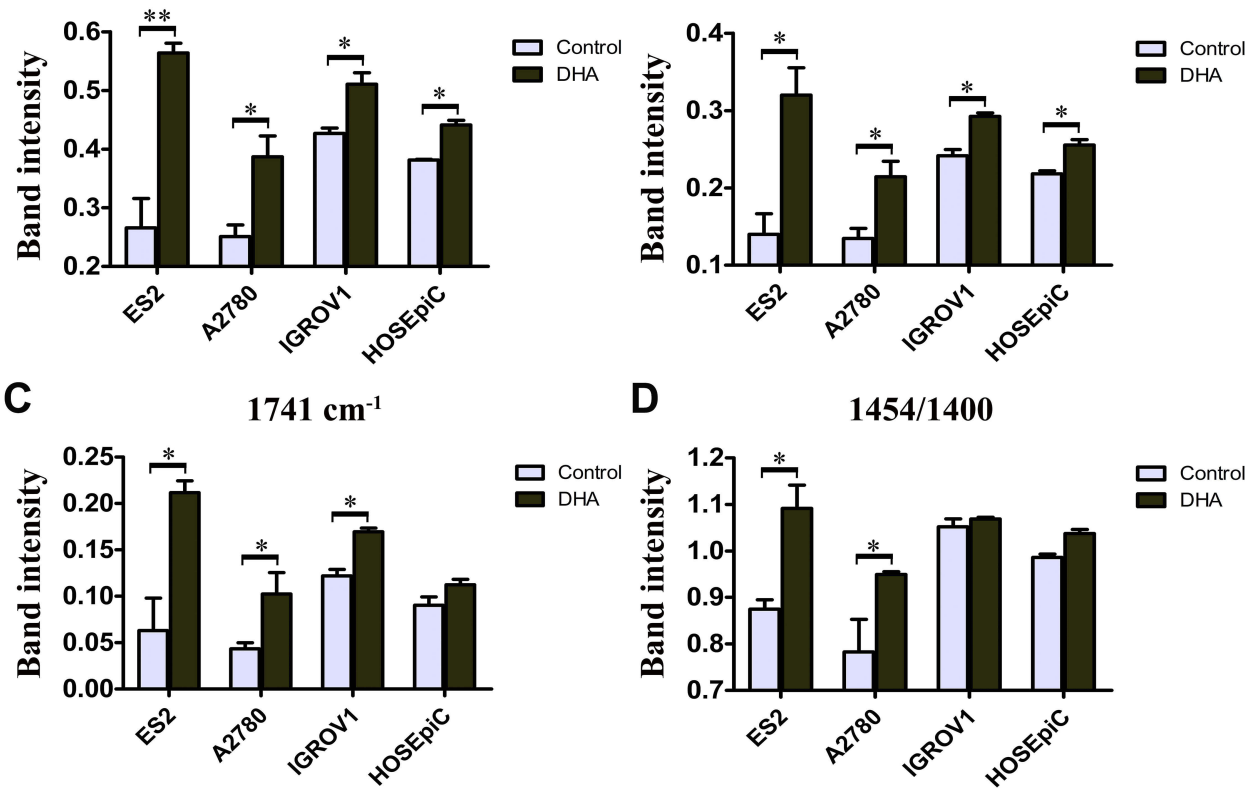

D

$1454 / 1400$

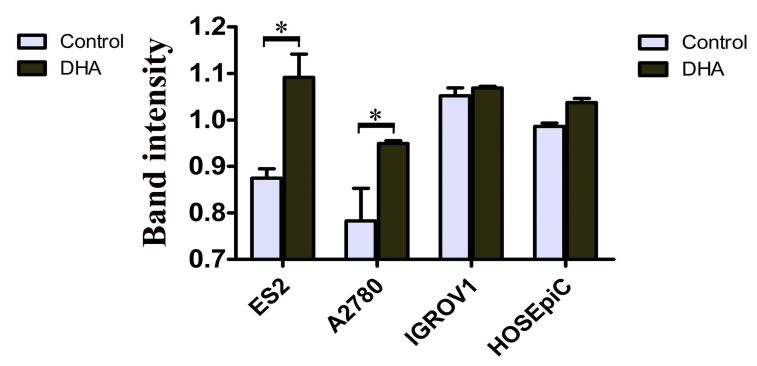

E

$1242 \mathrm{~cm}^{-1}$

F
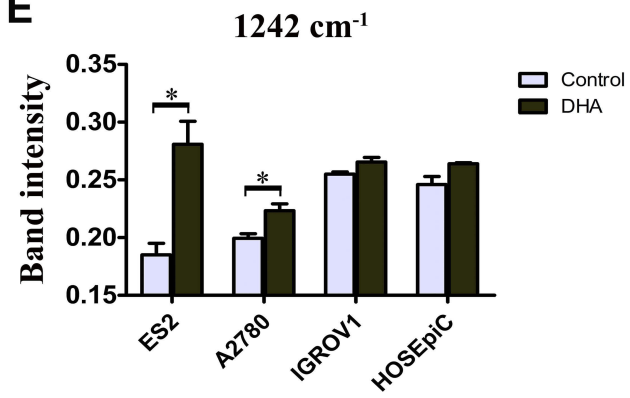

$\mathbf{F}$

$1086 \mathrm{~cm}^{-1}$

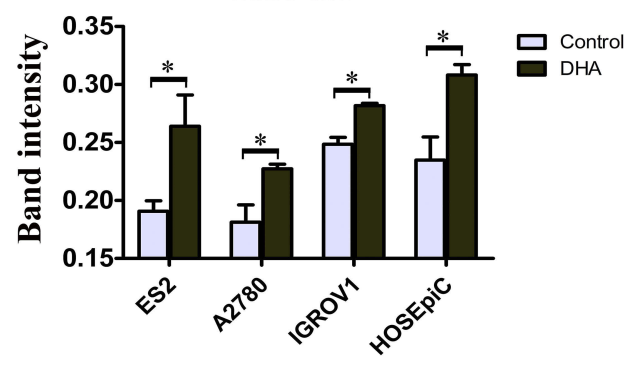

Figure 3 Intensity of specific bands of cells treated with or without DHA. Ovarian cancer cells (ES2, A2780 and IGROVI) and normal cells (HOSEpiC) were treated with or without DHA at the concentration corresponding to their IC50 for $48 \mathrm{hr}$. Relative intensities of specific bands of $2925 \mathrm{~cm}^{-1}(\mathbf{A}), 2854 \mathrm{~cm}^{-1}(\mathbf{B}), 174 \mathrm{I} \mathrm{cm}(\mathbf{C}), 1242 \mathrm{~cm}^{-1}$ (E) and $1086 \mathrm{~cm}^{-1}(\mathbf{F})$ as well as the ratio of $1454 / 1400$ (D) were calculated and compared. $* P<0.05 ; * * P<0.01$.

an increase at $1086 \mathrm{~cm}^{-1}$ in the four subtraction spectra and an increase at $1242 \mathrm{~cm}^{-1}$ in the ES2 and A2780 subtraction spectra were observed, while the band at around $1242 \mathrm{~cm}^{-1}$ appeared unchanged in the IGROV1 and HOSEpiC subtraction spectra, consistent with our above results. For the bands at around $1454 \mathrm{~cm}^{-1}$ and $1400 \mathrm{~cm}^{-1}$, a peak at around $1460 \mathrm{~cm}^{-1}$ and a nadir at around $1400 \mathrm{~cm}^{-1}$ were shown in each of the four subtraction spectra, suggesting an increase in the intensity ratio of 1454/1400. However, inconsistent results were found in the four subtraction spectra in regions $3600-3000 \mathrm{~cm}^{-1}$ ( $v_{\mathrm{N}-\mathrm{H}}$ and $v_{\mathrm{O}-\mathrm{H}}$ of protein), $1700-1500 \mathrm{~cm}^{-1}$ (protein amide I and amide II) and $<900 \mathrm{~cm}^{-1}$ (carbohydrates). The amide II bands were negative for the four subtraction spectra, and the amide I bands were negative except for the A2780 subtraction spectrum. For the HOSEpiC subtraction spectrum, the $1694 \mathrm{~cm}^{-1}$ band was notably positive. Therefore, the protein components were varied after DHA treatment.

\section{Discussion}

In previous studies it has been widely demonstrated the potential use of FTIR spectroscopy in identifying the properties of cells. $^{26,27}$ FTIR spectroscopy is able to capture changes in detailed cell signatures while cells respond to chemotherapeutics. $^{28}$ DHA, a derivative of ARS, is an effective antimalarial drug with only minor side effects. 5,6 Multiple studies have revealed that DHA also has significant effects against human tumors and is less toxic. ${ }^{29}$ It can inhibit ovarian cancer cell growth, modulate the cell cycle and induce apoptosis both in vitro and in vivo., ${ }^{9,10}$ However, the events that occur when DHA plays its antitumor role have yet to be fully investigated. Here, we presented the varying effects of DHA exposure in different ovarian cancer cells and a normal cell line by FTIR spectroscopy. Of note, ovarian cancer cells showed some molecular changes after treatment with DHA. Four main differences were found in 
A

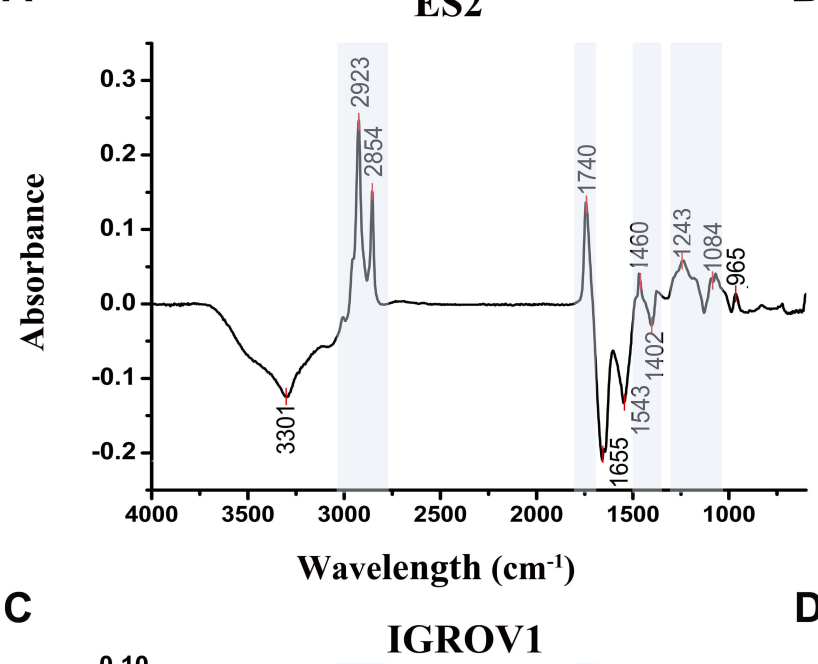

B

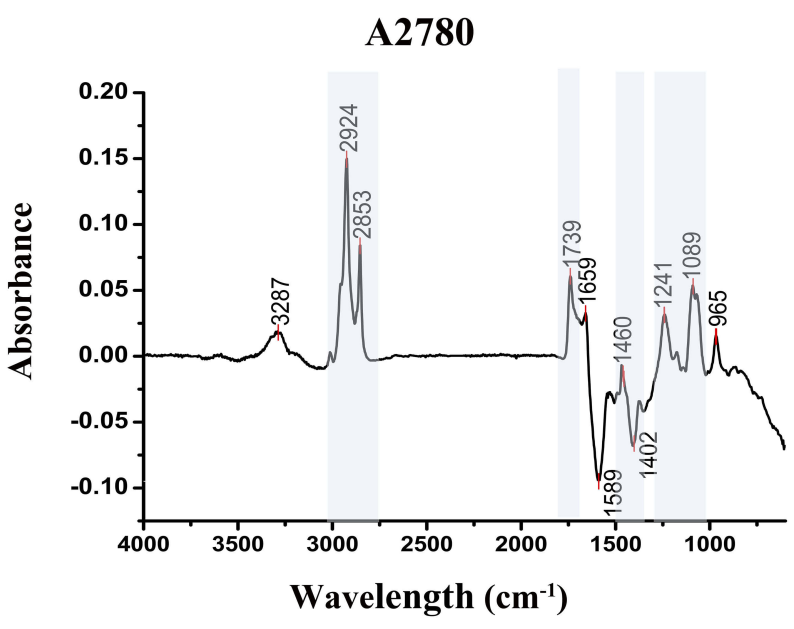

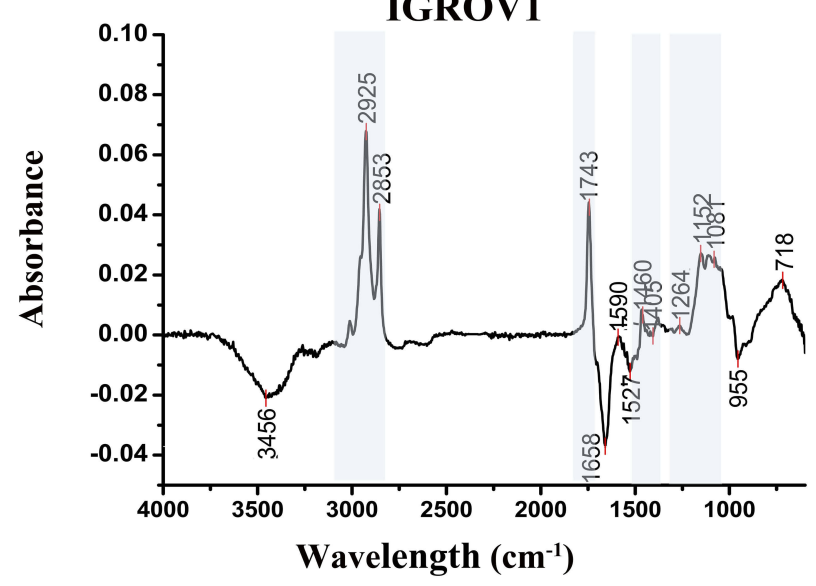

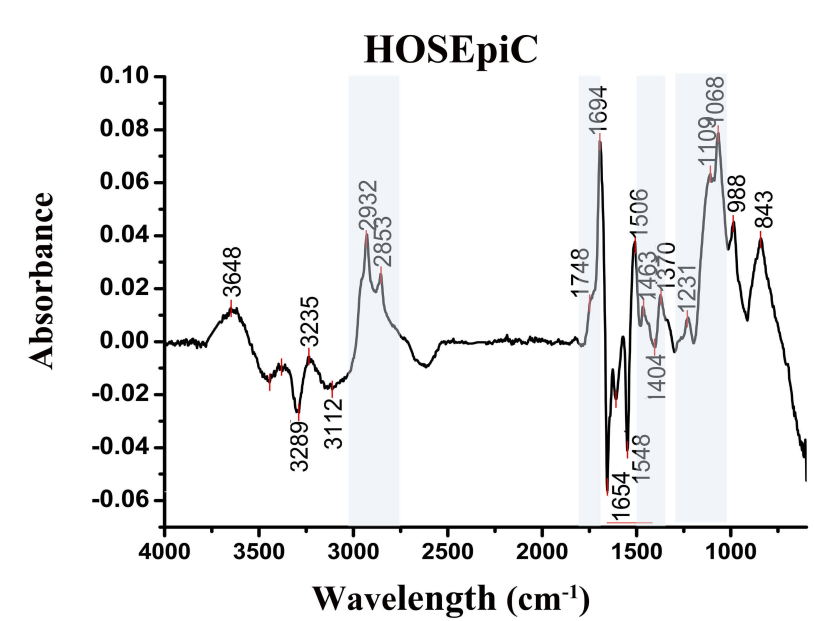

Figure 4 Subtraction spectrum of each of the cell lines treated with DHA vs vehicle control. Dominant differences in the subtraction spectra of the cell lines ES2 (A), A2780 (B), IGROVI (C) and HOSEpiC (D) after exposure to DHA, especially in the signals at around $2925 \mathrm{~cm}^{-1}, 2854 \mathrm{~cm}^{-1}, 1741 \mathrm{~cm}^{-1}, 1460 \mathrm{~cm}^{-1}$ and I400 cm as well as $1242 \mathrm{~cm}^{-1}$ and $1086 \mathrm{~cm}^{-1}$, are indicated in the blue background.

our study, including spectral changes in the regions of $3000-2800 \mathrm{~cm}^{-1}, 1800-1700 \mathrm{~cm}^{-1}, 1500-1300 \mathrm{~cm}^{-1}$ and $1300-900 \mathrm{~cm}^{-1}$.

The bands associated with cell lipids occur mainly in the $3000-2800 \mathrm{~cm}^{-1}$ and $1800-1700 \mathrm{~cm}^{-1}$ regions. ${ }^{17,20}$ Compared with control cells, DHA-treated cells of all of the cell lines showed an absorption increase at around $2925 \mathrm{~cm}^{-1}$, $2852 \mathrm{~cm}^{-1}$ and $1740 \mathrm{~cm}^{-1}$, indicating that lipid levels including phospholipids in the cell membrane increase during growth inhibition in these ovarian cancer cells. Many previous studies have reported an increase in the lipid-related absorbance in apoptotic or necrotic cells. ${ }^{30,31}$ Although neither of the two cell death modes involves similar membrane changes, the specific membrane events responsible for the increased lipid changes during each process are unknown. These changes might be associated with the variation of the relevant lipid signaling molecules during growth inhibition process, ${ }^{32,33}$ or might be attributable to the morphological changes in cell volume. ${ }^{21,34}$ Cell volume was reduced after DHA treatment. In fact, the decrease in cell volume is equivalent to a relative increase in surface area, which may lead to an increase in the phospholipid content.

Moreover, the increased lipid content during DHA treatment was also indicated by the relatively increased ratio of the intensity of the $\sim 1454 \mathrm{~cm}^{-1}$ to $\sim 1400 \mathrm{~cm}^{-1}$ bands. The difference in the band ratio (1454/1400) revealed a change in the $\mathrm{C}-\mathrm{O}(\mathrm{H})$-stretching pattern of the cells with DHAinduced growth arrest and the vehicle controls. These ratio increases caused by slow growth were consistent with our previous study, which showed that normal cells exhibited a higher 1454/1400 band ratio than ovarian cancer cells with malignant proliferation, ${ }^{23}$ indicating that this difference may have the potential to identify the effects of antitumor drugs or distinguish cells with different growth features. 
In the region $1300-900 \mathrm{~cm}^{-1}$, the bands near $1087 \mathrm{~cm}^{-1}$ and $1240 \mathrm{~cm}^{-1}$ originate, respectively, from the symmetric $\mathrm{PO}_{2}^{-}\left(v_{\mathrm{s}} \mathrm{PO}_{2}^{-}\right)$and asymmetric $\mathrm{PO}_{2}^{-}\left(v_{\mathrm{as}} \mathrm{PO}_{2}^{-}\right)$stretching vibrations of the phosphate groups that are part of the DNA backbone. $^{35}$ The relative band intensities of $1087 \mathrm{~cm}^{-1}$ and $1242 \mathrm{~cm}^{-1}$ are commonly applied to point out a change in the DNA content. Our data indicated that the cellular DNA content increased in DHA-treated cells. As DHA were wildly demonstrated to have an apoptosis-induce feature, these results were consistent with the findings of Jiangbing Zhou et al, ${ }^{36}$ where an increase in the peak area at $1087 \mathrm{~cm}^{-1}$ was observed in differentiated cells and apoptotic cells. However, the underlying mechanism requires further investigation.

\section{Conclusions}

In summary, our data indicate FTIR spectroscopy as a potential tool for distinguishing the growth inhibitory effect of DHA on ovarian cancer cells and normal cells. The changes are noted in three IR biomarkers: (1) an increase in lipid absorbance (in the regions of both $3000-2800 \mathrm{~cm}^{-1}$ and $1800-1700 \mathrm{~cm}^{-1}$ ); (2) an increase in the relative intensity ratio of 1454/1400; and (3) an increase in DNA absorbance. Furthermore, these changes were larger for cells that were more sensitive to DHA (ES2 and A2780 cells vs. IGROV1 and HOSEpiC cells). Because FTIR spectroscopy can provide distinctive molecular information with convenient sample processing, it may therefore be a promising new approach for the clinical monitoring of cell growth and the response to antitumor drugs in the future.

\section{Abbreviations}

FTIR, Fourier transform infrared; ARS, artemisinin; DHA, dihydroartemisinin; IC20, IC50 and IC $80: 20 \%, 50 \%$ and $80 \%$ inhibitory concentrations, respectively; HOSEpiC, human ovarian surface epithelial cell line; FBS, fetal bovine serum; MCT, mercury cadmium telluride.

\section{Acknowledgment}

This study was supported by the Chinese Academy of Medical Sciences Initiative for Innovative Medicine (CAMS-2017-I2M-1-002) and the National Natural Science Foundation of China (NO. 81502254).

\section{Disclosure}

The authors report no conflicts of interest in this work.

\section{References}

1. Bray F, Ferlay J, Soerjomataram I, Siegel RL, Torre LA, Jemal A. Global cancer statistics 2018: GLOBOCAN estimates of incidence and mortality worldwide for 36 cancers in 185 countries. CA Cancer J Clin. 2018;68(6):394-424. doi:10.3322/caac.v68.6

2. Su Z, Graybill WS, Zhu Y. Detection and monitoring of ovarian cancer. Clin Chim Acta. 2013;415:341-345. doi:10.1016/j.cca.2012.10.058

3. Yap TA, Carden CP, Kaye SB. Beyond chemotherapy: targeted therapies in ovarian cancer. Nat Rev Cancer. 2009;9(3):167-181. doi: $10.1038 / \mathrm{nrc} 2583$

4. Janzen DM, Tiourin E, Salehi JA, et al. An apoptosis-enhancing drug overcomes platinum resistance in a tumour-initiating subpopulation of ovarian cancer. Nat Commun. 2015;6:7956. doi:10.1038/ ncomms 8956

5. Klayman DL. Qinghaosu (artemisinin): an antimalarial drug from China. Science. 1985;228(4703):1049-1055. doi:10.1126/science.3887571

6. Miller LH, Su X. Artemisinin: discovery from the Chinese herbal garden. Cell. 2011;146(6):855-858. doi:10.1016/j.cell.2011.08.024

7. Firestone GL, Sundar SN. Anticancer activities of artemisinin and its bioactive derivatives. Expert Rev Mol Med. 2009;11:e32. doi:10.1017/ S1462399409001239

8. Chen H, Sun B, Wang S, et al. Growth inhibitory effects of dihydroartemisinin on pancreatic cancer cells: involvement of cell cycle arrest and inactivation of nuclear factor-kappaB. J Cancer Res Clin Oncol. 2010;136(6):897-903. doi:10.1007/s00432-009-0731-0

9. Singh NP, Lai H. Selective toxicity of dihydroartemisinin and holotransferrin toward human breast cancer cells. Life Sci. 2001;70 (1):49-56. doi:10.1016/S0024-3205(01)01372-8

10. He Q, Shi J, Shen XL, et al. Dihydroartemisinin upregulates death receptor 5 expression and cooperates with TRAIL to induce apoptosis in human prostate cancer cells. Cancer Biol Ther. 2010;9 (10):819-824. doi:10.4161/cbt.9.10.11552

11. Li X, Zhou Y, Liu Y, et al. Preclinical efficacy and safety assessment of artemisinin-chemotherapeutic agent conjugates for ovarian cancer. EBioMedicine. 2016;14:44-54. doi:10.1016/j.ebiom.2016.11.026

12. Nunes JJ, Pandey SK, Yadav A, Goel S, Ateeq B. Targeting NF-kappa B signaling by artesunate restores sensitivity of castrate-resistant prostate cancer cells to antiandrogens. Neoplasia. 2017;19(4):333-345. doi:10.1016/j.neo.2017.02.002

13. Kumari K, Keshari S, Sengupta D, Sabat SC, Mishra SK. Transcriptome analysis of genes associated with breast cancer cell motility in response to artemisinin treatment. BMC Cancer. 2017;17 (1):858. doi:10.1186/s12885-017-3863-7

14. Blazquez AG, Fernandez-Dolon M, Sanchez-Vicente L, et al. Novel artemisinin derivatives with potential usefulness against liver/colon cancer and viral hepatitis. Bioorg Med Chem. 2013;21(14):4432-4441. doi:10.1016/j.bmc.2013.04.059

15. Martin FL. Shining a new light into molecular workings. Nat Methods. 2011;8(5):385-387. doi:10.1038/nmeth.1594

16. Baker MJ, Trevisan J, Bassan P, et al. Using fourier transform IR spectroscopy to analyze biological materials. Nat Protoc. 2014;9 (8):1771-1791. doi:10.1038/nprot.2014.110

17. Petibois C, Deleris G. Chemical mapping of tumor progression by FT-IR imaging: towards molecular histopathology. Trends Biotechnol. 2006;24(10):455-462. doi:10.1016/j.tibtech.2006.08.005

18. Theophilou G, Lima KM, Martin-Hirsch PL, Stringfellow HF, Martin FL. ATR-FTIR spectroscopy coupled with chemometric analysis discriminates normal, borderline and malignant ovarian tissue: classifying subtypes of human cancer. Analyst. 2016;141(2):585-594. doi:10.1039/ C5AN00939A

19. Derenne A, Van Hemelryck V, Lamoral-Theys D, Kiss R, Goormaghtigh E. FTIR spectroscopy: a new valuable tool to classify the effects of polyphenolic compounds on cancer cells. Biochim Biophys Acta. 2013;1832(1):46-56. doi:10.1016/j.bbadis.2012.10.010 
20. Wood BR, Chiriboga L, Yee H, Quinn MA, McNaughton D, Diem M. Fourier transform infrared (FTIR) spectral mapping of the cervical transformation zone, and dysplastic squamous epithelium. Gynecol Oncol. 2004;93(1):59-68. doi:10.1016/j.ygyno.2003.12.028

21. Wu BB, Gong YP, Wu XH, et al. Fourier transform infrared spectroscopy for the distinction of MCF-7 cells treated with different concentrations of 5-fluorouracil. J Transl Med. 2015;13:108. doi:10.1186/s12967-0150468-2

22. Gao Y, Huo X, Dong L, et al. Fourier transform infrared microspectroscopy monitoring of 5-fluorouracil-induced apoptosis in SW620 colon cancer cells. Mol Med Rep. 2015;11(4):2585-2591. doi:10. 3892/mmr.2014.3088

23. Li L, Bi X, Sun H, et al. Characterization of ovarian cancer cells and tissues by fourier transform infrared spectroscopy. $J$ Ovarian Res. 2018;11(1):64. doi:10.1186/s13048-018-0434-8

24. Guler G, Acikgoz E, Karabay Yavasoglu NU, Bakan B, Goormaghtigh E, Aktug H. Deciphering the biochemical similarities and differences among mouse embryonic stem cells, somatic and cancer cells using ATR-FTIR spectroscopy. Analyst. 2018;143 (7):1624-1634. doi:10.1039/C8AN00017D

25. Gezici O, Demir I, Demircan A, Unlu N, Karaarslan M. SubtractiveFTIR spectroscopy to characterize organic matter in lignite samples from different depths. Spectrochim Acta a Mol Biomol Spectrosc. 2012;96:63-69. doi:10.1016/j.saa.2012.05.004

26. Hughes C, Brown MD, Ball FJ, et al. Highlighting a need to distinguish cell cycle signatures from cellular responses to chemotherapeutics in SR-FTIR spectroscopy. Analyst. 2012;137(24):5736-5742. doi:10.1039/ c2an35633c

27. Gaigneaux A, Goormaghtigh E. A new dimension for cell identification by FTIR spectroscopy: depth profiling in attenuated total reflection. Analyst. 2013;138(14):4070-4075. doi:10.1039/c3an00193h
28. Giorgini E, Sabbatini S, Rocchetti R, et al. In vitro FTIR microspectroscopy analysis of primary oral squamous carcinoma cells treated with cisplatin and 5-fluorouracil: a new spectroscopic approach for studying the drug-cell interaction. Analyst. 2018;143(14):3317-3326. doi:10.1039/C8AN00602D

29. Wong YK, $\mathrm{Xu} \mathrm{C}$, Kalesh KA, et al. Artemisinin as an anticancer drug: recent advances in target profiling and mechanisms of action. Med Res Rev. 2017;37(6):1492-1517. doi:10.1002/med.2017.37.issue-6

30. Liu KZ, Jia L, Kelsey SM, Newland AC, Mantsch HH. Quantitative determination of apoptosis on leukemia cells by infrared spectroscopy. Apoptosis. 2001;6(4):269-278. doi:10.1023/A:1011383408381

31. Zelig U, Kapelushnik J, Moreh R, Mordechai S, Nathan I. Diagnosis of cell death by means of infrared spectroscopy. Biophys J. 2009;97 (7):2107-2114. doi:10.1016/j.bpj.2009.07.026

32. Spiegel S. Sphingosine 1-phosphate: a prototype of a new class of second messengers. J Leukoc Biol. 1999;65(3):341-344. doi:10.1002/jlb. 1999.65.issue-3

33. Cantrell DA. Phosphoinositide 3-kinase signalling pathways. J Cell Sci. 2001;114(Pt 8):1439-1445.

34. Gasparri F, Muzio M. Monitoring of apoptosis of HL60 cells by fourier-transform infrared spectroscopy. Biochem J. 2003;369(Pt 2):239-248. doi:10.1042/bj20021021

35. Banyay M, Sarkar M, Graslund A. A library of IR bands of nucleic acids in solution. Biophys Chem. 2003;104(2):477-488. doi:10.1016/ S0301-4622(03)00035-8

36. Zhou J, Wang Z, Sun S, Liu M, Zhang H. A rapid method for detecting conformational changes during differentiation and apoptosis of HL60 cells by fourier-transform infrared spectroscopy. Biotechnol Appl Biochem. 2001;33(Pt 2):127-132. doi:10.1042/BA20000074

\section{Publish your work in this journal}

Cancer Management and Research is an international, peer-reviewed open access journal focusing on cancer research and the optimal use of preventative and integrated treatment interventions to achieve improved outcomes, enhanced survival and quality of life for the cancer patient.
The manuscript management system is completely online and includes a very quick and fair peer-review system, which is all easy to use. Visit http://www.dovepress.com/testimonials.php to read real quotes from published authors. 